\title{
OXYGEN SATURATION OF STERNAL MARROW BLOOD IN POLYCYTHEMIA VERA ${ }^{1}$
}

\author{
By BERNARD M. SCHWARTZ AND DANIEL STATS \\ (From the Medical Services, Cardiovascular Research Group, and the Hematology Laboratory, \\ The Mount Sinai Hospital, Neze York City)
}

(Received for publication March 9, 1949)

The polycythemia observed at high altitudes and in certain forms of pulmonary and congenital heart disease has led to the acceptance of the view that anoxia is an erythropoietic stimulus. In polycythemia vera, however, the oxygen saturation of the arterial blood has been found to be normal. Observers have, therefore, sought in the bone marrow itself for evidence of anoxia in this disease. Reznikoff et al. (1) demonstrated changes in the capillaries and arterioles in the bone marrow of patients with polycythemia vera and postulated decreased blood flow with subsequent anoxia as the erythropoietic stimulus. Chemical evidence of such anoxia has as yet not been obtained.

It has likewise been maintained that marrow anoxia is the stimulus to red cell production in anemia, as for example, after hemorrhage. Recently, however, Grant and Root $(2,3)$ have determined the percentage saturation and oxygen tension of bone marrow blood in dogs made anemic by bleeding and found no significant difference from the control animals.

These considerations led us to a study of the oxygen content in bone marrow blood in various diseases in man, adapting the method of Grant and Root.

After the studies to be reported in this paper had been completed, the work of Berk, Burchenal, Wood, and Castle (4) on the same subject was published.

\section{MATERIALS AND METHODS}

Fifty-two sets of determinations in 50 patients are presented here. From each patient, within a period of several minutes, specimens of bone marrow blood and brachial arterial blood were obtained. In 35 instances antecubital venous blood was drawn without stasis. All bloods were chilled until the analyses were performed.

At the time of withdrawal of the blood specimens for analysis, the patients were recumbent in bed, having

1 Aided by a grant from the Linde Air Products Company. rested quietly for at least ten minutes. Experiments were usually performed between 9 and 10 o'clock in the morning, about two hours after breakfast. More attention was not paid to the establishment of absolutely basal conditions because the act of sternal marrow puncture induced a degree of anxiety in most patients which was of far greater moment than the other factors affecting the basal state.

The sternal bone marrow aspiration was performed by the usual technique at the level of the second interspace with a number 17 bone marrow needle and stylet. After the marrow had been entered, the stylet was withdrawn. In only two patients, one with polycythemia vera and one with an hemangioma of the spleen (not included in the present series), was there a spontaneous welling up of blood into the hub of the needle. In the other patients, a preliminary gentle aspiration with a $10 \mathrm{cc}$. syringe was performed until blood just appeared in the syringe. The syringe was then discarded and the patients were instructed to perform a momentary Valsalva experiment when necessary, whereupon bone marrow blood was seen to rise into the hub. The tip of a Roughton-Scholander micro-pipette, containing dried heparin, was immediately inserted well below the level of the blood to the junction of the hub with the needle proper. The operator's finger was held over the opposite end in order to prevent blood in contact with air from entering the pipette. Forty cu. mm. were aspirated and transferred to a RoughtonScholander analyzer for immediate determination of oxygen content. From $0.75 \mathrm{cc}$. to $1.0 \mathrm{cc}$. of bone marrow blood was then withdrawn with gentle suction into a 2 cc. syringe containing dried heparin for the determination of oxygen capacity.

Oxygen determinations were performed by the method of Roughton and Scholander (5). For the capacity measurement blood was saturated with oxygen by the aeration of 0.5 to $1.0 \mathrm{cc}$. for 15 minutes in the syringe in which the specimen had been collected. Correction for dissolved oxygen in both the saturated and unsaturated specimens was made using the figures of Sendroy et al. (6).

The patients were divided into four groups, namely, controls, patients with polycythemia vera, anemia and anoxic anoxia. The "control" group consisted of afebrile patients, some of whom were convalescent from a variety of diseases and who manifested no hematologic, cardiovascular, or pulmonary abnormalities. The polycythemia vera group consisted of all patients with this diagnosis, regardless of the stage of therapy. The anemics consisted of patients whose arterial oxygen capacity was less than 
15 volumes per cent, corresponding to a hemoglobin content of 11.0 grams per $100 \mathrm{cc}$. The anoxic group included patients whose arterial oxygen saturation was below normal. In addition to the anoxic anoxia which all patients in this group manifested, some were presumed to have stagnant anoxia on the basis of congestive heart failure.

In the collection of "bone marrow blood" for the determination of oxygen content and capacity several possible sources of error are to be considered:

1. As indicated previously a preliminary aspiration with a $10 \mathrm{cc}$. syringe and the performance of the Valsalva maneuver were usually necessary in order to obtain a free flow of bone marrow blood into the hub of the needle. Did these pressures induce changes in the oxygen content of the bone marrow blood obtained? For a brief period the level of bone marrow blood in the hub was exposed to air. Did this brief exposure also induce changes in the oxygen content of the specimen drawn? It is likely that whatever error was introduced affected the controls and the test groups similarly. It was believed that such changes took place only at the surface of the blood column and that errors from these sources could be eliminated by inserting the tip of the pipette well below the level of the blood. This opinion was substantiated by subjecting blood to similar treatment in a dummy experiment.

2. Another source of error is that "bone marrow blood" is not a relatively constant mixture like peripheral blood. When material is aspirated through a needle in the bone marrow, a variable proportion of marrow elements, stagnant red blood cells, and actively flowing blood is obtained. This is evident grossly in that some bone marrow specimens appear homogeneous whereas in others yellowish grey particles are seen. In addition, changes in circulation may have occurred at the tip of the needle in the marrow cavity. An indication of the magnitude of these errors can be obtained by comparing the oxygen capacities of bone marrow and peripheral blood in the same individual. The value, arterial blood oxygen capacity minus bone marrow blood oxygen capacity, had an extreme range from +2.3 to -1.1 volumes per cent. The mean difference, however, was +0.3 volumes per cent, just beyond the error of the method, showing that there was a slight dilution by bone marrow elements. Using the method of Grant (7), in a number of instances, we determined the oxygen capacity of bone marrow blood drawn before and after the removal of $1 \mathrm{cc}$. and found a similar variation. It should be pointed out in this connection that Grant and Root (2) found an average difference of +1.3 volumes per cent between venous and bone marrow oxygen capacity in dogs. As an indication of the degree of error brought about by variation in the oxygen capacity of bone marrow blood, we have calculated the percentage saturation of bone marrow blood on the basis of the capacity of both bone marrow and arterial blood. The mean and the standard deviation in the control and in the other groups were not changed significantly by either method of calculation. We have therefore used the figures for percentage saturation of bone marrow blood calculated on the basis of bone marrow capacity in the presentation of our results.

\section{RESULTS}

The results in individual cases are shown in Tables I through IV. Table V compares the results in the four groups of cases. The oxygen contents are given in volumes per cent. Letter $A$ refers to brachial arterial blood and letters BM to sternal bone marrow blood.

TABLE I

Control patients

\begin{tabular}{|c|c|c|c|c|c|c|c|}
\hline \multirow{2}{*}{$\begin{array}{l}\text { Age, } \\
\text { Sex }\end{array}$} & \multicolumn{2}{|c|}{$\begin{array}{l}\text { Oxygen } \\
\text { capacity }\end{array}$} & \multicolumn{2}{|c|}{$\begin{array}{l}\text { Oxygen } \\
\text { content }\end{array}$} & \multicolumn{2}{|c|}{$\begin{array}{l}\text { Percentage } \\
\text { saturation }\end{array}$} & \multirow{2}{*}{$\begin{array}{c}\begin{array}{c}\text { Differ- } \\
\text { ence } \\
\text { oxygen } \\
\text { content }\end{array} \\
\begin{array}{c}\text { minus } \\
\text { mM }\end{array}\end{array}$} \\
\hline & A & BM & A & BM & A & $\mathbf{B M}$ & \\
\hline $62 \mathrm{M}$ & 20.3 & 20.8 & 20.0 & 16.3 & 97 & 78 & 3.7 \\
\hline $52 \mathrm{M}$ & 15.9 & 15.7 & 15.3 & 12.7 & 94 & 80 & 2.6 \\
\hline $14 \mathrm{M}$ & 19.8 & 19.5 & & 17.1 & - & 87 & - \\
\hline $27 \mathrm{M}$ & 16.5 & 16.1 & 16.3 & 11.5 & 97 & 71 & 4.8 \\
\hline $69 \mathrm{M}$ & 16.6 & 16.5 & 15.6 & 14.3 & 92 & 86 & 1.3 \\
\hline $41 \mathrm{M}$ & 21.0 & 20.7 & 20.4 & 15.7 & 96 & 75 & 4.7 \\
\hline $60 \mathrm{M}$ & 18.0 & 18.6 & 17.8 & 15.9 & 97 & 85 & 1.9 \\
\hline $21 \mathrm{M}$ & 20.3 & 19.3 & 19.4 & 16. & 94 & 8 & 3.4 \\
\hline $28 \mathrm{M}$ & 20.3 & 20.5 & 19.9 & 18.0 & 97 & 87 & 1.9 \\
\hline $54 \mathrm{M}$ & 17.5 & 17.1 & 16.5 & 11.4 & 93 & 66 & 5.1 \\
\hline $49 \mathrm{M}$ & 17.2 & 16.8 & 16.7 & 13.2 & 95 & 79 & 3.5 \\
\hline $18 \mathrm{M}$ & 20.4 & 20. & 20.6 & 15 & 99.5 & 72 & 5.6 \\
\hline $49 \mathrm{M}$ & 20.3 & 20. & 19.6 & 17. & 95 & 8. & 2.3 \\
\hline $63 \mathrm{M}$ & 19.8 & 19. & 19.5 & 16.3 & 97 & 83 & 3.2 \\
\hline $49 \mathrm{~F}$ & 16.5 & 16 & 16.1 & 12.6 & 96 & 77 & 3.5 \\
\hline $16 \mathrm{M}$ & 19.2 & 18 & 18.7 & 15. & 96 & 8 & 2.9 \\
\hline $59 \mathrm{M}$ & 16.3 & 16. & 15.4 & 13.0 & 93 & 7 & 2.4 \\
\hline $27 \mathrm{M}$ & 16.8 & 17. & 17.1 & 12.6 & 100 & 70 & 4.5 \\
\hline $63 \mathrm{M}$ & 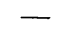 & 17 & 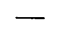 & 13.4 & - & 76 & - \\
\hline $46 \mathrm{~F}$ & 16.9 & 15 & 16.9 & 10.3 & 98 & 65 & 6.6 \\
\hline $60 \mathrm{~F}$ & - & 16 & - & 12. & 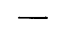 & 74 & 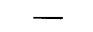 \\
\hline $33 \mathrm{M}$ & 18.9 & 19.0 & 18.3 & 15.5 & 95 & 81 & 2.8 \\
\hline $64 \mathrm{M}$ & 18.6 & 18. & 17.5 & 15. & 93 & 82 & 2.4 \\
\hline $55 \mathrm{M}$ & 16.6 & 16. & 16.3 & 14. & 96 & 86 & 2.1 \\
\hline $50 \mathrm{M}$ & 16.6 & 17. & 16.3 & 13.5 & 96 & 78 & 2.8 \\
\hline
\end{tabular}

Percentage saturation of bone marrow blood with oxygen: It is evident that there was a wide variation in the percentage saturation of bone marrow blood with oxygen in all four groups, this being especially pronounced in the control group. The values for patients with anemia tended to fall in the lower range of the control values, but the difference between the means was not statistically significant. The values for the anoxic patients had a similar, but somewhat wider range, and the mean was somewhat lower. The difference between the means of the control and anoxic groups was on the border of significance ( $p$ was between 
TABLE II

Polycythemia vera patients

\begin{tabular}{|c|c|c|c|c|c|c|c|c|c|c|}
\hline \multirow{2}{*}{$\begin{array}{l}\text { Age, } \\
\text { Sex }\end{array}$} & \multirow{2}{*}{$\begin{array}{l}\text { Duration } \\
\text { disease }\end{array}$} & \multirow{2}{*}{$\begin{array}{l}\text { Previous } \\
\text { treatment }\end{array}$} & \multirow{2}{*}{ Hematocrit } & \multicolumn{2}{|c|}{ Oxygen capacity } & \multicolumn{2}{|c|}{ Oxygen content } & \multicolumn{2}{|c|}{ Percentage saturation } & \multirow{2}{*}{$\frac{\begin{array}{c}\text { Difference } \\
\text { oxygen } \\
\text { content }\end{array}}{\text { A minus BM }}$} \\
\hline & & & & A & BM & A & BM & A & вм & \\
\hline & years & & & & & & & & & \\
\hline $60 \mathrm{~F}$ & 9 & $1,2,4$ & 57 & 17.1 & 16.4 & 16.9 & 14.7 & 97 & 88 & 2.2 \\
\hline $56 \mathrm{~F}$ & 1 & 2,4 & 67 & 23.4 & 23.3 & 23.0 & 19.8 & 97 & 85 & 3.2 \\
\hline $77 \mathrm{~F}$ & 5 & 2,4 & 67 & 24.2 & 24.0 & 23.2 & 22.0 & 95 & 91 & 1.2 \\
\hline $65 \mathrm{M}$ & 9 & 2,4 & 61.5 & 18.6 & 18.5 & 18.7 & 17.7 & 99 & 94 & 1.0 \\
\hline $64 \mathrm{M}$ & 7 & $2,3,4$ & 62 & 25.6 & 24.7 & 24.8 & 24.3 & 96 & 97 & 0.5 \\
\hline $54 \mathrm{M}$ & 12 & $1,2,4$ & 48 & 17.3 & 16.8 & 17.0 & 13.5 & 97 & 80 & 3.5 \\
\hline $55 \mathrm{~F}^{*}$ & 1 & None & 70 & 23.4 & 22.5 & 23.2 & 21.8 & 98 & 96 & 1.4 \\
\hline $55 \mathrm{~F}^{*}$ & 1 & None & 69 & 22.3 & 21.5 & 21.4 & 20.5 & 95 & 95 & 0.9 \\
\hline $55 \mathrm{~F}^{*}$ & 1 & 2 & 64 & 21.2 & 21.3 & 20.8 & 17.7 & 97 & 83 & 3.1 \\
\hline $56 \mathrm{M}$ & 10 & 4 & 70 & 26.3 & 26.5 & 25.7 & 22.7 & 97 & 85 & 3.0 \\
\hline $55 \mathrm{M}$ & 12 & $1,2,4$ & 60 & 18.8 & 19.0 & 18.0 & 16.8 & 94 & 87 & 1.2 \\
\hline
\end{tabular}

* Same patient.

Previous treatment:

1. Total body irradiation.

2. Phlebotomies.

3. Phenylhydrazine.

4. $\mathrm{P}^{32}$.

TABLE III

Anemic patients

\begin{tabular}{|c|c|c|c|c|c|c|c|}
\hline \multirow{2}{*}{$\begin{array}{l}\text { Age, } \\
\text { Sex }\end{array}$} & \multicolumn{2}{|c|}{$\begin{array}{l}\text { Oxygen } \\
\text { capacity }\end{array}$} & \multicolumn{2}{|c|}{$\begin{array}{l}\text { Oxygen } \\
\text { content }\end{array}$} & \multicolumn{2}{|c|}{$\begin{array}{l}\text { Percentage } \\
\text { saturation }\end{array}$} & \multirow{2}{*}{$\frac{\begin{array}{c}\text { Difference } \\
\text { oxygen } \\
\text { content }\end{array}}{\mathrm{A}_{\mathrm{BM}}^{\text {minus }}}$} \\
\hline & A & BM & A & $\mathrm{BM}$ & A & $\mathrm{BM}$ & \\
\hline $39 \mathrm{M}$ & 11.8 & 12.1 & 12.0 & 9.1 & 99 & 74 & 29 \\
\hline $62 \mathrm{~F}$ & 12.0 & 11.6 & 11.9 & 9.1 & 97 & 78 & 2.8 \\
\hline $60 \mathrm{M}$ & 9.9 & 9.7 & 9.6 & 7.8 & 94 & 79 & 1.8 \\
\hline $40 \mathrm{~F}$ & 7.6 & 7.1 & 7. & 4.9 & 97 & 68 & 2.8 \\
\hline $43 \mathrm{~F}$ & 5.0 & 5.3 & 4.7 & 4.1 & 90 & 75 & 0.6 \\
\hline $56 \mathrm{M}$ & 11.0 & 10.6 & 10.9 & 7.1 & 96 & 66 & 3.8 \\
\hline $58 \mathrm{M}$ & 10.7 & 11.3 & 10.3 & 9.0 & 94 & 79 & 1.3 \\
\hline
\end{tabular}

The first and last cases are pernicious anemia; the others are hypochromic anemia.
0.05 and 0.01$).^{2}$ On the other hand, the values for patients with polycythemia vera were higher than those of the control group, although there was overlapping in the treated polycythemics with relatively low oxygen capacities. The difference between the means was statistically significant (p was less than 0.001). ${ }^{2} A$ fortiori, the difference between the means in the polycythemia vera group and the anoxic group was highly significant.

Arterial-bone marrow oxygen difference: The difference between the oxygen content of arterial

$2 \mathrm{p}$ is the probability that the observed difference between the means is due to chance, as calculated by Fisher's " $\mathrm{t}$ " test.

TABLE IV

Anoxic patients

\begin{tabular}{|c|c|c|c|c|c|c|c|c|}
\hline \multirow{2}{*}{ Diagnosis } & \multirow{2}{*}{$\begin{array}{l}\text { Age, } \\
\text { Sex }\end{array}$} & \multicolumn{2}{|c|}{ Oxygen capacity } & \multicolumn{2}{|c|}{ Oxygen content } & \multicolumn{2}{|c|}{ Percentage saturation } & \multirow{2}{*}{$\frac{\begin{array}{c}\text { Difference } \\
\text { oxygen } \\
\text { content }\end{array}}{\underbrace{\text { minus }}_{\mathrm{BM}}}$} \\
\hline & & A & $\mathbf{B M}$ & $\mathbf{A}$ & BM & $\mathbf{A}$ & BM & \\
\hline $\begin{array}{l}\text { Pulmonary fibrosis } \\
\text { Emphysema } \\
\text { Congestive heart failure } \\
\text { Pulmonary fibrosis } \\
\text { Congestive heart failure } \\
\text { Cor pulmonale } \\
\text { Tetralogy of Fallot } \\
\text { Pulmonary fibrosis }\end{array}$ & $\begin{array}{ll}52 & \mathrm{M} \\
62 & \mathrm{M} \\
63 & \mathrm{M} \\
60 & \mathrm{M} \\
60 & \mathrm{~F} \\
54 & \mathrm{M} \\
30 & \mathrm{~F} \\
42 & \mathrm{M}\end{array}$ & $\begin{array}{l}17.9 \\
21.7 \\
17.1 \\
21.7 \\
21.0 \\
23.5 \\
25.1 \\
21.5\end{array}$ & $\begin{array}{l}\overline{22.1} \\
15.8 \\
21.2 \\
21.1 \\
23.0 \\
25.6 \\
20.9\end{array}$ & $\begin{array}{l}16.6 \\
17.9 \\
14.4 \\
18.7 \\
19.1 \\
17.5 \\
22.6 \\
19.9\end{array}$ & $\begin{array}{l}12.0 \\
14.0 \\
10.1 \\
15.1 \\
17.3 \\
17.1 \\
18.6 \\
16.4\end{array}$ & $\begin{array}{l}92 \\
83 \\
84 \\
85 \\
90 \\
74 \\
89 \\
92\end{array}$ & $\begin{array}{l}-63 \\
70 \\
71 \\
82 \\
74 \\
72 \\
78\end{array}$ & $\begin{array}{l}4.6 \\
3.9 \\
4.3 \\
3.6 \\
1.8 \\
0.4 \\
4.0 \\
3.5\end{array}$ \\
\hline
\end{tabular}


and bone marrow blood (A-BM difference) dis- played a similar wide range of variation, greatest in the control and anoxic groups. The A-BM values for the anemics tended to fall in the lower range of normal, but the difference between the means was not significant. The patients with anoxia, due at least in part to the heterogeneous make-up of the group, showed no significant difference from the controls. The A-BM values for patients with polycythemia vera, however, were in general lower than the controls, although there was overlapping. The difference between the means in the latter two groups was statistically significant ( $\mathrm{p}$ was between 0.01 and 0.001$)^{2}{ }^{2}$

The values for antecubital venous blood oxygen content displayed the wide range of variation previously reported by others. With few exceptions, the venous oxygen content was lower than the bone marrow content.

TABLE $V$

Mean values for all patients

\begin{tabular}{l|r|r|r|r|r|r}
\hline \hline & \multicolumn{3}{|c|}{$\begin{array}{c}\text { Percentage } \\
\text { saturation bone } \\
\text { marrow blood }\end{array}$} & \multicolumn{3}{|c}{$\begin{array}{c}\text { Difference } \\
\text { oxygen content } \\
\text { A minus BM }\end{array}$} \\
\cline { 2 - 7 } & No. & Mean & S.D. & No. & Mean & S.D. \\
\hline $\begin{array}{l}\text { Control } \\
\text { Polycy themia vera } \\
\text { Anemia } \\
\text { Anoxia }\end{array}$ & 25 & 78.8 & 6.44 & 22 & 3.35 & 1.347 \\
& 7 & 88.3 & 5.52 & 11 & 1.93 & 1.094 \\
& 7 & 72.9 & 6.07 & 8 & 3.31 & 1.489 \\
\hline
\end{tabular}

S.D.-Standard deviation.

\section{DISCUSSION}

The wide range of variation in the oxygen content and percentage saturation of bone marrow blood found in this study confirms the results of Grant and Root $(2,3)$ in dogs and of Berk and coworkers (4) in man.

By the present methods, with their limitations as discussed above, it was not possible to demonstrate bone marrow anoxia in polycythemia vera. In this respect, our findings are in agreement with those of Berk et al. However, whereas they found no significant difference in the mean value of the percentage saturation of bone marrow blood in the controls and in polycythemia vera, our findings show a significantly higher value for the latter. In common with Grant and Root (2), we confined our analyses of bone marrow blood oxygen content to the first several drops of blood appearing in the needle. Berk et al. withdrew $5 \mathrm{cc}$. by syringe in their "old" technique and $1 \mathrm{cc}$. in their "new" technique performing analyses upon this blood. It is significant that our average value for percentage saturation in the controls, 78.7 per cent, was essentially the same as that obtained by Grant and Root in control dogs. The corresponding value for normals found by Berk et al. was 88.6 per cent by their "new" method, which is not significantly different from their value for polycythemias, 87.3 per cent, nor from our value for polycythemia vera, 88.6 per cent. If difference in technique accounts for the varying findings, it is not clear in the comparison of these results why this difference affected only the normals, where we differed by 9.9 per cent, while identical figures were obtained in polycythemia vera. A possible explanation may be that in polycythemia vera the bone marrow is hyperplastic and extraordinarily vascular so that the first cubic centimeter of blood brought into the syringe may represent bone marrow blood. On the other hand, in normal patients, where the bone marrow is not hyperplastic nor unduly vascular, only a portion of this cubic centimeter may come directly from the marrow. The remainder may be drawn in from extra-marrow sources. In support of this explanation is the fact that in four controls, we have found the oxygen content of bone marrow blood drawn after the removal of 1 cc. to be higher than the oxygen content of blood obtained before such removal. This finding, however, is at variance with the results obtained by Grant and Root in dogs, where successive bone marrow specimens showed the same oxygen content.

The other difference in technique, namely, that Berk et al. secured a spontaneous flow of marrow blood by having their patients turn to one side whereas we induced flow by gentle suction, does not, in our opinion, account for the different results because of the dummy experiments performed by both sets of investigators, which showed no change as a result of such manipulations.

The percentage saturation of bone marrow blood in polycythemia vera would be higher than normal even if the arterial-bone marrow oxygen difference were the same in the two groups. Actually, the A-BM difference was lower in the polycythemic 
group, thus accentuating the difference in percentage saturation. Ordinarily decreased arteriovenous oxygen difference implies increased blood flow, provided oxygen consumption is not decreased. Overall oxygen consumption in polycythemia vera is increased or normal. We are aware of no in vivo studies of oxygen consumption of bone marrow itself. One would expect an increased oxygen consumption in hyperplastic marrow. Therefore, increased blood flow compatible with an hyperplastic, highly vascular marrow may be present. This would impart to the circulation in the marrow in polycythemia vera a unique character since there is evidence that the general circulation in this disease is slowed. The theoretical possibility remains, however, that oxygen consumption of bone marrow in polycythemia vera is decreased (histotoxic type of anoxia or arteriovenous shunting). In this case the low $A-B M$ difference would not necessarily indicate increased blood flow.

In agreement with the findings of Grant and Root in post-hemorrhagic anemia in dogs we have been unable to demonstrate a significant difference from the controls in the percentage saturation or arterial-bone marrow oxygen difference of a small number of cases of pernicious and hypochromic anemia. This may be due, in part, to the fact that our methods are not sensitive enough to detect small differences in the face of great normal variation.

In patients with anoxic anoxia the method was adequate to detect low percentage saturation values in the bone marrow blood. That they were not lower is due possibly to various compensatory factors, such as increased blood flow and increased oxygen capacity.

\section{SUMMARY AND CONCLUSIONS}

1. Oxygen content, capacity, and percentage saturation of bone marrow blood were determined in man in a group of controls and in patients with polycythemia vera, anemia, and anoxic anoxia. The limitations of the method are discussed.
2. The percentage saturation of bone marrow blood was greater and the arterial-bone marrow blood oxygen difference was smaller in patients with polycythemia vera than in controls. This finding does not support the theory that there is a local bone marrow anoxia due to decreased blood flow in polycythemia vera, but is compatible with either increased blood flow or decreased oxygen utilization by the marrow in this disease.

3. No significant differences were found between anemias and controls, in a small number of cases.

4. In patients with anoxic anoxia the percentage saturation of bone marrow blood with oxygen was lower than in the controls.

\section{ACKNOWLEDGMENTS}

We are indebted to Miss Micheline Weil for her conscientious technical assistance.

We wish to express our appreciation to Dr. Marcy L. Sussman for his continued interest and helpfulness.

\section{BIBLIOGRAPHY}

1. Reznikoff, P., Foot, N. C., and Bethea, J. M., Etiologic and pathologic factors in polycythemia vera. Am. J. M. Sc., 1935, 189, 753.

2. Grant, W. C., and Root, W. S., The relation of $\mathrm{O}_{2}$ in bone marrow blood to post-hemorrhagic erythropoiesis. Am. J. Physiol., 1947, 150, 618.

3. Grant, W. C., Oxygen saturation in bone marrow, and in arterial and venous blood during prolonged hemorrhagic erythropoiesis. Am. J. Physiol., 1948, 153, 521.

4. Berk, L., Burchenal, J. H., Wood, T., and Castle, W. B., Oxygen saturation of sternal marrow blood with special reference to pathogenesis of polycythemia. Proc. Soc. Exper. Biol. \& Med., 1948, $69,316$.

5. Roughton, F. J. W., and Scholander, P. F., Micro gasometric estimation of the blood gases. I. Oxygen. J. Biol. Chem., 1943, 148, 541.

6. Sendroy, J., Jr., Dillon, R. T., and Van Slyke, D. D., Studies of gas and electrolyte equilibria in blood. XIX. The solubility and physical state of uncombined oxygen in blood. J. Biol. Chem., 1934, 105, 597.

7. Grant, W. C., Determination of $\mathrm{O}_{2}$ capacity on 39.3 cubic millimeters of blood. Proc. Soc. Exper. Biol. \& Med., 1947, 66, 60. 